\title{
A Rhodamine-Based Fluorescent Thermometer Exhibiting Selective Emission Enhancement at a Specific Temperature Range
}

\author{
Yasuhiro Shiraishi,* Ryo Miyamoto, Xuan Zhang and Takayuki Hirai \\ Research Center for Solar Energy Chemistry, and Division of Chemical Engineering, \\ Graduate School of Engineering Science, Osaka University, Toyonaka 560-8531, Japan \\ E-mail:shiraish@cheng.es.osaka-u.ac.jp.
}

\section{Supporting Information}

\section{Materials}

1. This was synthesized in a manner similar to literature procedure. ${ }^{[\mathrm{S} 1]}$ Rhodamine $\mathrm{B}$ hydrochloride $(0.6 \mathrm{~g}, 1.3 \mathrm{mmol})$ and ethylenediamine $(1.0 \mathrm{~g}, 16.6 \mathrm{mmol})$ were dissolved in EtOH $(50 \mathrm{~mL})$ and refluxed for $12 \mathrm{~h}$. The solvent was removed by evaporation, and the residue was dissolved in an aqueous $\mathrm{HCl}$ solution $(1 \mathrm{M}, 50 \mathrm{~mL})$. An aqueous $\mathrm{NaOH}$ solution (1 M) was added carefully to the solution with magnetic stirring until the beginning of an appearance of pink precipitate. The precipitate was recovered by filtration, washed thoroughly with water, and then dried in vacuo, yielding $\mathbf{1}$ as a pink-white fluffy powder $(0.52 \mathrm{~g}, 78 \%): \delta_{\mathrm{H}}\left(270 \mathrm{MHz}, \mathrm{CDCl}_{3}, \mathrm{Me}_{4} \mathrm{Si}\right): 1.16\left(\mathrm{t}, 12 \mathrm{H},-\mathrm{CH}_{3}\right.$, ethyl), $2.95(\mathrm{t}, 2 \mathrm{H}$, $\mathrm{NH}_{2} \mathrm{CH}_{2-}$, polyamine), 3.33 (q, $10 \mathrm{H},-\mathrm{NCH}_{2}-$, ethyl, $-\mathrm{NCH}_{2-}$, polyamine), 6.29-6.39 (m, $6 \mathrm{H}$, $\operatorname{ArH}), 7.07$ (s, 1H, ArH), 7.45 (t, 2H, ArH), 7.85 (d, 1H, ArH). $\delta_{\mathrm{C}}\left(67.8 \mathrm{MHz}, \mathrm{CDCl}_{3}\right.$, $\left.\mathrm{Me}_{4} \mathrm{Si}\right): 170.20$, 153.64, 153.24, 149.16, 132.93, 129.94, 128.18, 123.83, 123.05, 108.78, 104.04, 98.09, 66.63, 44.44, 41.14, 39.93, 12.74. FAB-MS: Calcd for $\mathrm{C}_{30} \mathrm{H}_{36} \mathrm{~N}_{4} \mathrm{O}_{2}$ : 484.28. Found: $m / z 485.0\left(\mathrm{M}+\mathrm{H}^{+}\right)$. The ${ }^{1} \mathrm{H}$ and ${ }^{13} \mathrm{C}$ NMR spectra of 1 were shown in Figures $\mathrm{S} 7$ and S8, respectively.

Poly(NIPAM-co-NASI). This was synthesized in a manner similar to literature procedure. ${ }^{[\mathrm{S} 2]}$ NIPAM (0.61 g, $5.4 \mathrm{mmol}$ ), $N$-hydroxysuccinimide (NASI, $15.4 \mathrm{mg}, 0.091 \mathrm{mmol}$ ), and AIBN $(15 \mathrm{mg}, 0.088 \mathrm{mmol})$ were dissolved in $t-\mathrm{BuOH}(5 \mathrm{~mL})$. The solution was degassed by twice freeze-pump-thaw cycles. The solution was heated to $70{ }^{\circ} \mathrm{C}$ under $\mathrm{N}_{2}$ atmosphere and stirred for $15 \mathrm{~h}$, and then cooled to room temperature. The solvent was removed by evaporation. The polymer formed was recovered by twice precipitation with $\mathrm{MeOH}(1 \mathrm{~mL})$ and diethyl ether 
(100 mL). After drying, poly(NIPAM-co-NASI) was obtained as a white solid (0.52 g, $83 \%$ ). Poly(NIPAM-co-RD). poly(NIPAM-co-NASI) (0.39 g) and 1 (26.4 mg, $0.055 \mathrm{mmol})$ were dissolved in DMF $(10 \mathrm{~mL})$. The solution was stirred at room temperature for $24 \mathrm{~h}$ under $\mathrm{N}_{2}$ atmosphere. Isopropylamine $(0.5 \mathrm{~mL})$ was added to the solution and stirred for $5 \mathrm{~h}$ at room temperature. After removal of solvents by evaporation, the residue was purified by twice reprecipitation with $\mathrm{MeOH}(1 \mathrm{~mL})$ and diethyl ether $(100 \mathrm{~mL})$, affording a light pink solid of poly(NIPAM-co-RD) $(0.37 \mathrm{~g}, 89 \%): \delta_{\mathrm{H}}\left(270 \mathrm{MHz} ; \mathrm{CDCl}_{3} ; \mathrm{Me}_{4} \mathrm{Si}\right): 1.14$ (s, br, 6H, $\left.-\mathrm{C}\left(\mathrm{CH}_{3}\right)_{2}\right), 1.2-2.2\left(\mathrm{~m}, 3 \mathrm{H},-\mathrm{C} H \mathrm{CH}_{2}-\right), 4.00(\mathrm{~s}, \mathrm{br}, 1 \mathrm{H},-\mathrm{CH}-)$. The ratio $(x / y)$ of poly(NIPAM $\left.{ }_{x}-c o-\mathrm{RB}_{y}\right)$ was estimated by comparison of absorbance $\left(A_{341}\right)$ with $\mathbf{1}$ dissolved in THF at $298 \mathrm{~K}$.

\section{Methods}

All spectroscopic measurements were carried out using a $10 \mathrm{~mm}$ path length quartz cell. Fluorescence spectra were measured on a Hitachi F-4500 fluorescence spectrophotometer $\left(\lambda_{\text {exc }}=530 \mathrm{~nm} ; \lambda_{\mathrm{em}}=580 \mathrm{~nm}\right)$ with a temperature controller. Absorption spectra were measured on an UV-visible photodiode-array spectrophotometer (Shimadzu; Multispec-1500) with a temperature controller (Shimadzu; S-1700). All measurements were carried out in the presence of $\mathrm{NaClO}_{4}$ to maintain the ionic strength of the solution $(I=0.15 \mathrm{M}) .{ }^{1} \mathrm{H}$ and ${ }^{13} \mathrm{C}$ NMR spectra were recorded by a JEOL JNM-GSX270 Excalibur. FAB MS spectra were obtained by a JEOL JMS 700 Mass Spectrometer. Light scattering measurements were carried out by dynamic laser scattering spectrometer (LB-500, HORIBA) (detection range, 3 nm-6 $\mu \mathrm{m}$ ) and static laser scattering spectrometer (LA-910, HORIBA) (detection range 0.5-700 $\mu \mathrm{m})$. Molecular weight of the polymers was determined by GPC using a Shimadzu SCL-10A Vp system equipped with a LC-10AD Vp pump (Shimadzu) and a refractive index detector RID-10A (Shimadzu), with GPC-805 column (Shimadzu). The oven temperature was $40{ }^{\circ} \mathrm{C}$, and THF was used as the carrier solvent (flow rate: $0.6 \mathrm{ml} \mathrm{m^{-1 } ) .}{ }^{[\mathrm{S} 3]}$

\section{References}

[S1] Xiang, Y.; Tong, A. Org. Lett. 2006, 8, 1549-1552.

[S2] Winnik, F. M. Macromolecules 1990, 23, 233-242.

[S3] Bontempo, D.; Maynard, H. D. J. Am. Chem. Soc. 2005, 127, 6508-6509. 

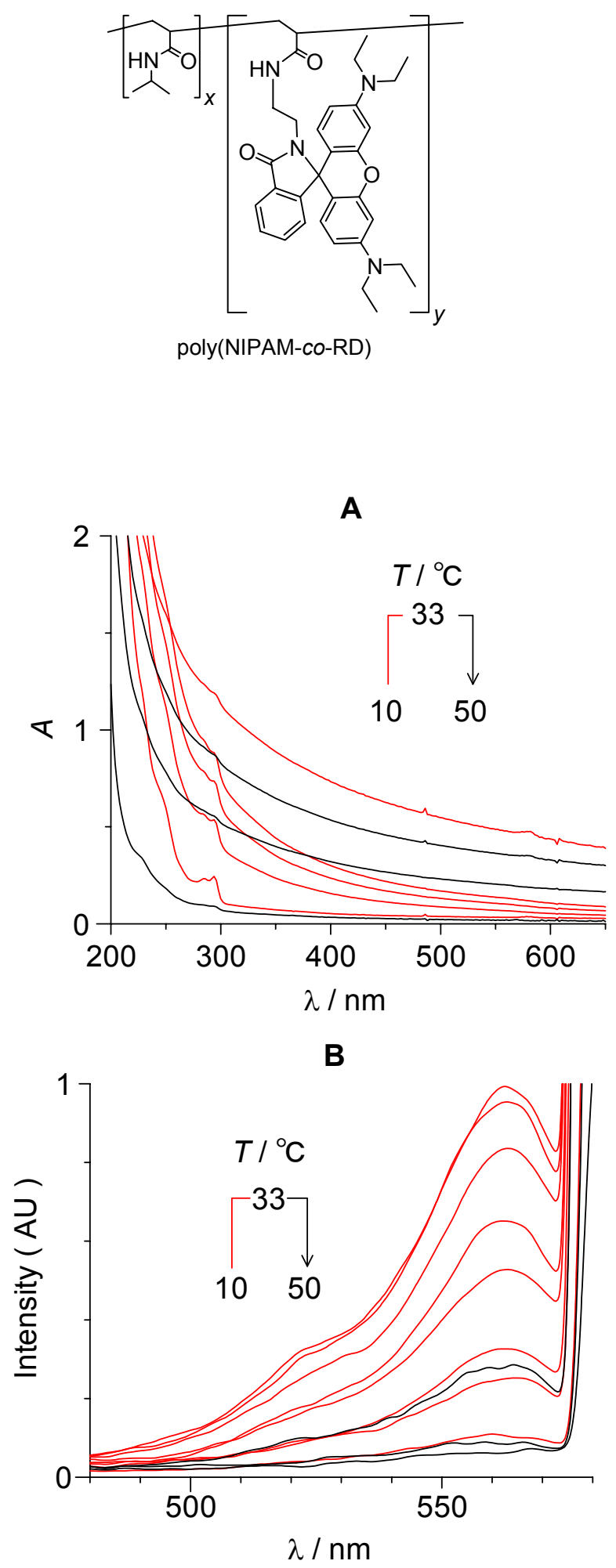

Figure S1. Temperature-dependent change in (A) absorption and (B) excitation spectra $\left(\lambda_{\mathrm{em}}=580\right.$ $\mathrm{nm})$ of poly(NIPAM-co-RD) dissolved in aqueous $\mathrm{NaClO}_{4}(0.15 \mathrm{M})$ solution of $\mathrm{pH} 2$. The measurements were done during heating sequence. 

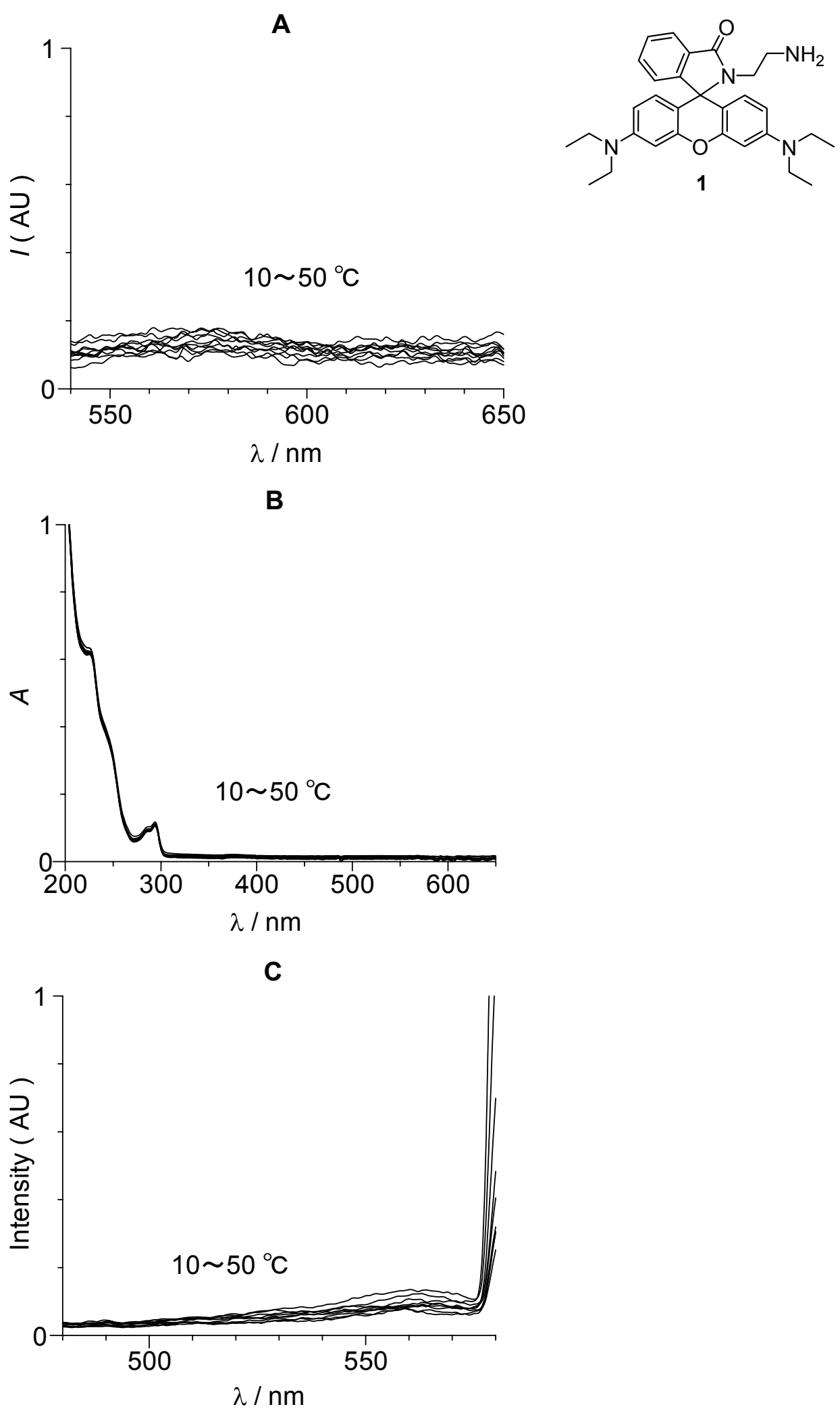

Figure S2. Temperature-dependent change in (A) fluorescence $\left(\lambda_{\text {exc }}=530 \mathrm{~nm}\right)$, (B) absorption, and (C) excitation spectra $\left(\lambda_{\mathrm{em}}=580 \mathrm{~nm}\right)$ of 1 measured in aqueous $\mathrm{NaClO}_{4}(0.15 \mathrm{M})$ solution of $\mathrm{pH} 2$. The measurements were done during heating sequence. 

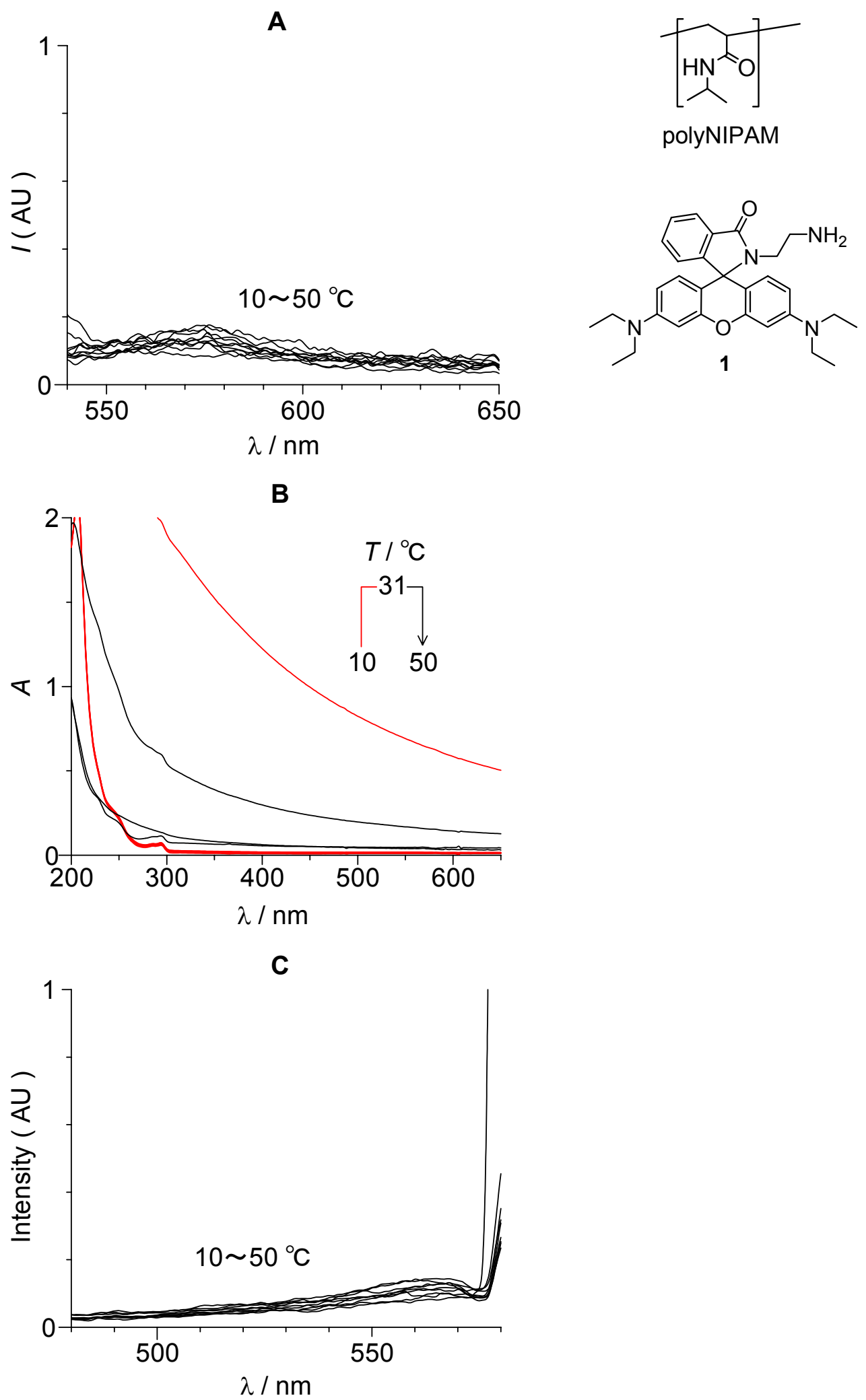

Figure S3. Temperature-dependent change in (A) fluorescence $\left(\lambda_{\text {exc }}=530 \mathrm{~nm}\right)$, (B) absorption, and (C) excitation spectra $\left(\lambda_{\mathrm{em}}=580 \mathrm{~nm}\right)$ of 1 measured in aqueous $\mathrm{NaClO}_{4}(0.15 \mathrm{M})$ solution of $\mathrm{pH} 2$ together with RD-free polyNIPAM. The measurements were done during heating sequence. 

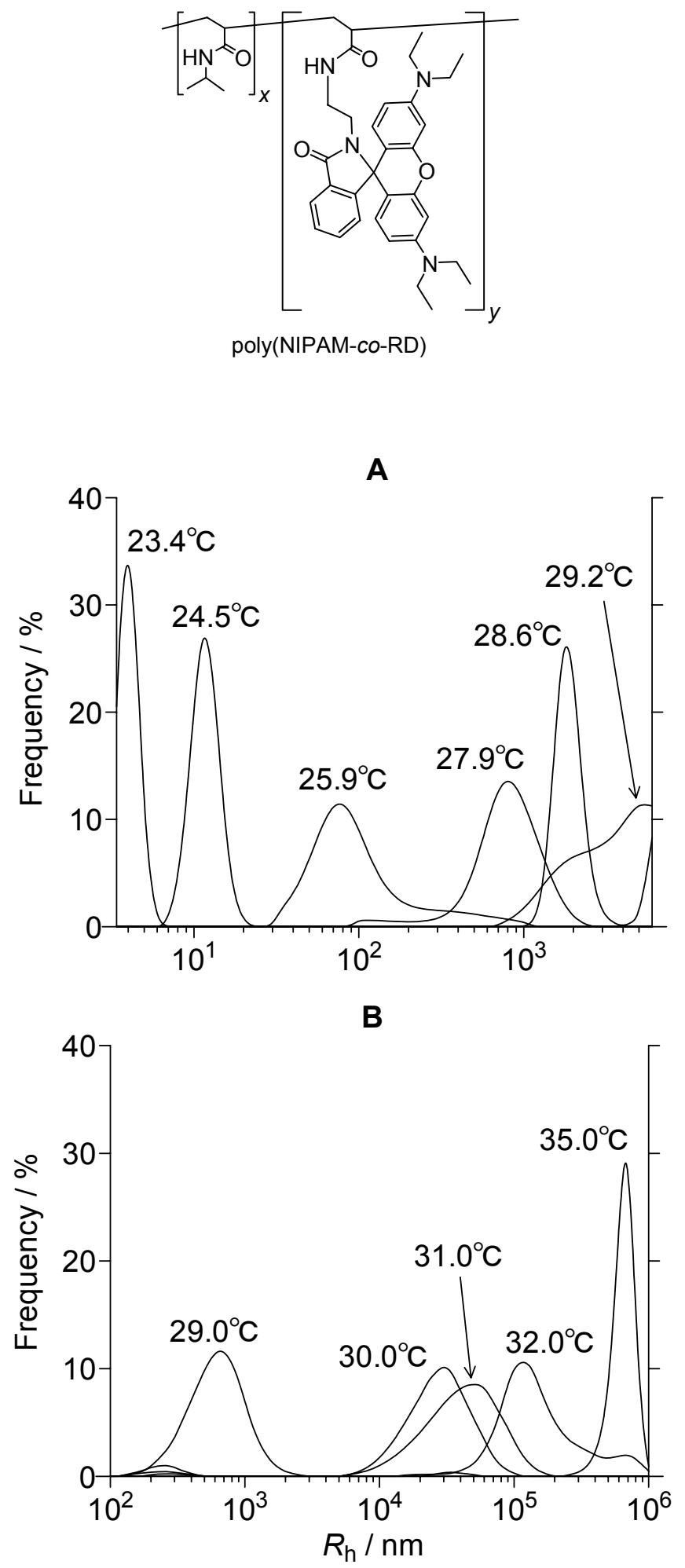

Figure S4. Temperature-dependent change in distribution of hydrodynamic radius $\left(R_{\mathrm{h}}\right)$ of poly(NIPAM-co-RD) dissolved in aqueous solution of $\mathrm{pH} 2$. The measurements were done during heating sequence. The $R_{\mathrm{h}}$ data were obtained by (A) dynamic and (B) static (Mie) laser scattering methods, respectively. 


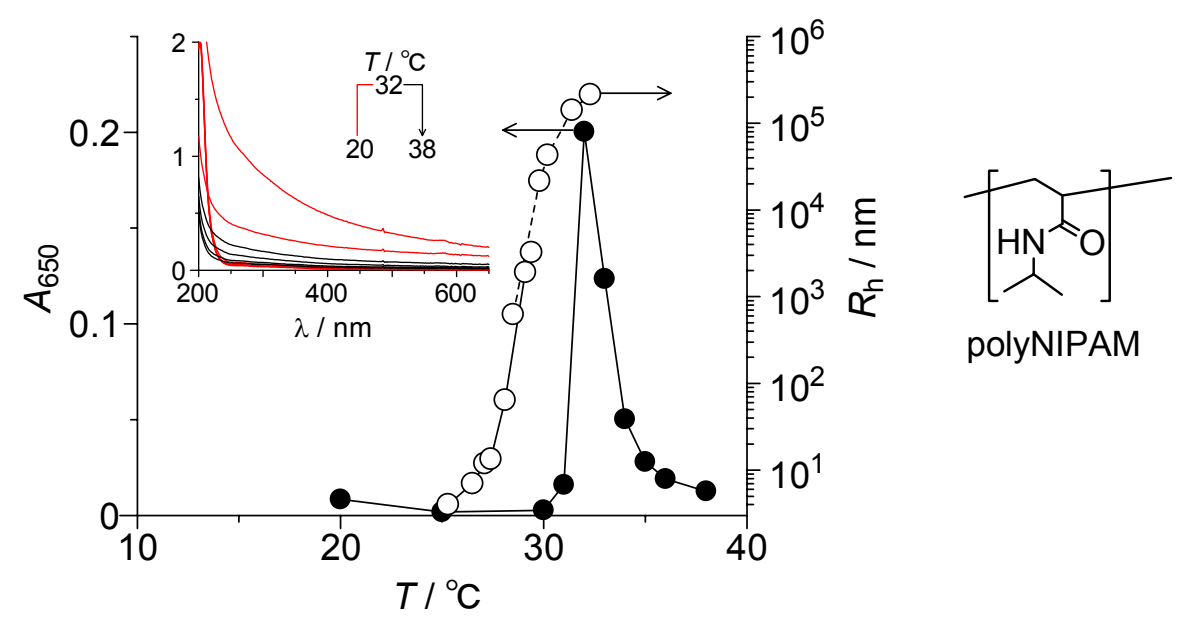

Figure S5. Temperature-dependent change in (black) turbidity $\left(A_{650}\right)$ and (white) hydrodynamic radius $\left(R_{\mathrm{h}}\right)$ of polyNIPAM in aqueous solution of $\mathrm{pH} 2$. The measurements were done during heating sequence. The $R_{\mathrm{h}}$ data for solid and dotted lines were obtained by dynamic and static (Mie) laser scattering methods. The $R_{\mathrm{h}}$ distribution data: see Figure S6. (Inset) Change in absorption spectra.
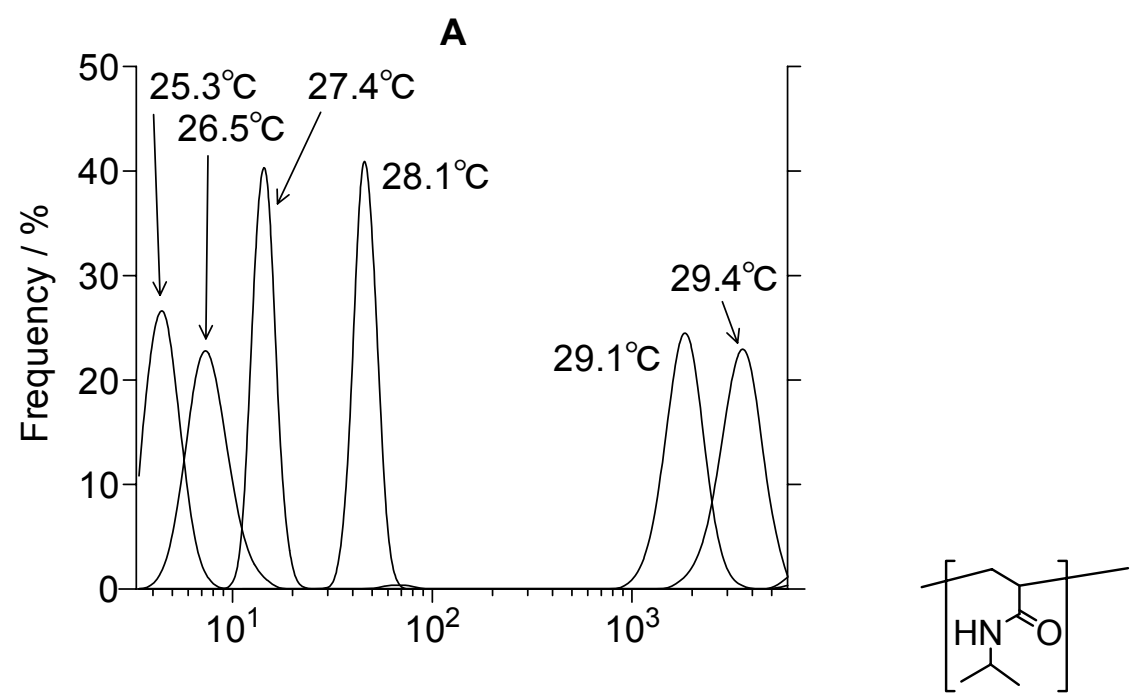

B

polyNIPAM

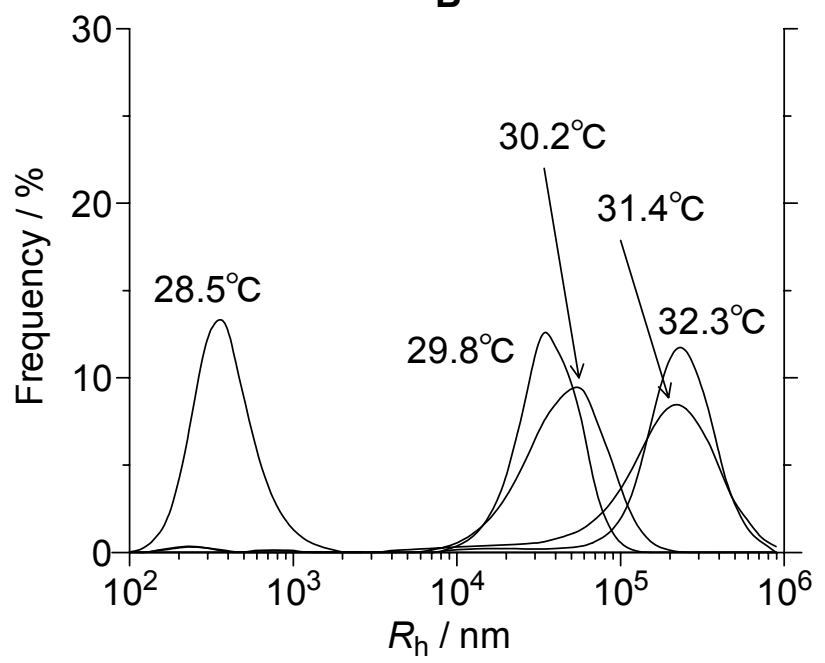

Figure S6. Temperature-dependent change in distribution of hydrodynamic radius $\left(R_{\mathrm{h}}\right)$ of polyNIPAM dissolved in aqueous solution of $\mathrm{pH} 2$. The $R_{\mathrm{h}}$ data were obtained by (A) dynamic and (B) static (Mie) laser scattering methods, respectively. 


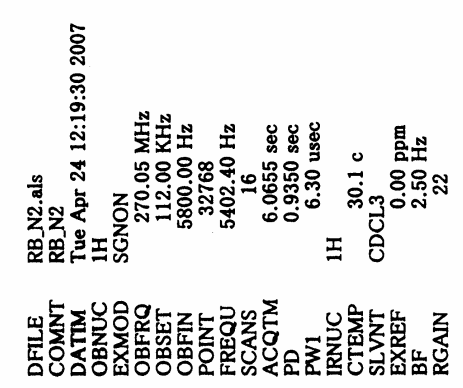

$00^{\circ} 0$

$9 I^{2} \mathrm{I}$

$96^{\circ}$

$\varepsilon \varepsilon^{*} \varepsilon$

$68 \cdot 9$

20.2

$9 F^{\circ} 2$
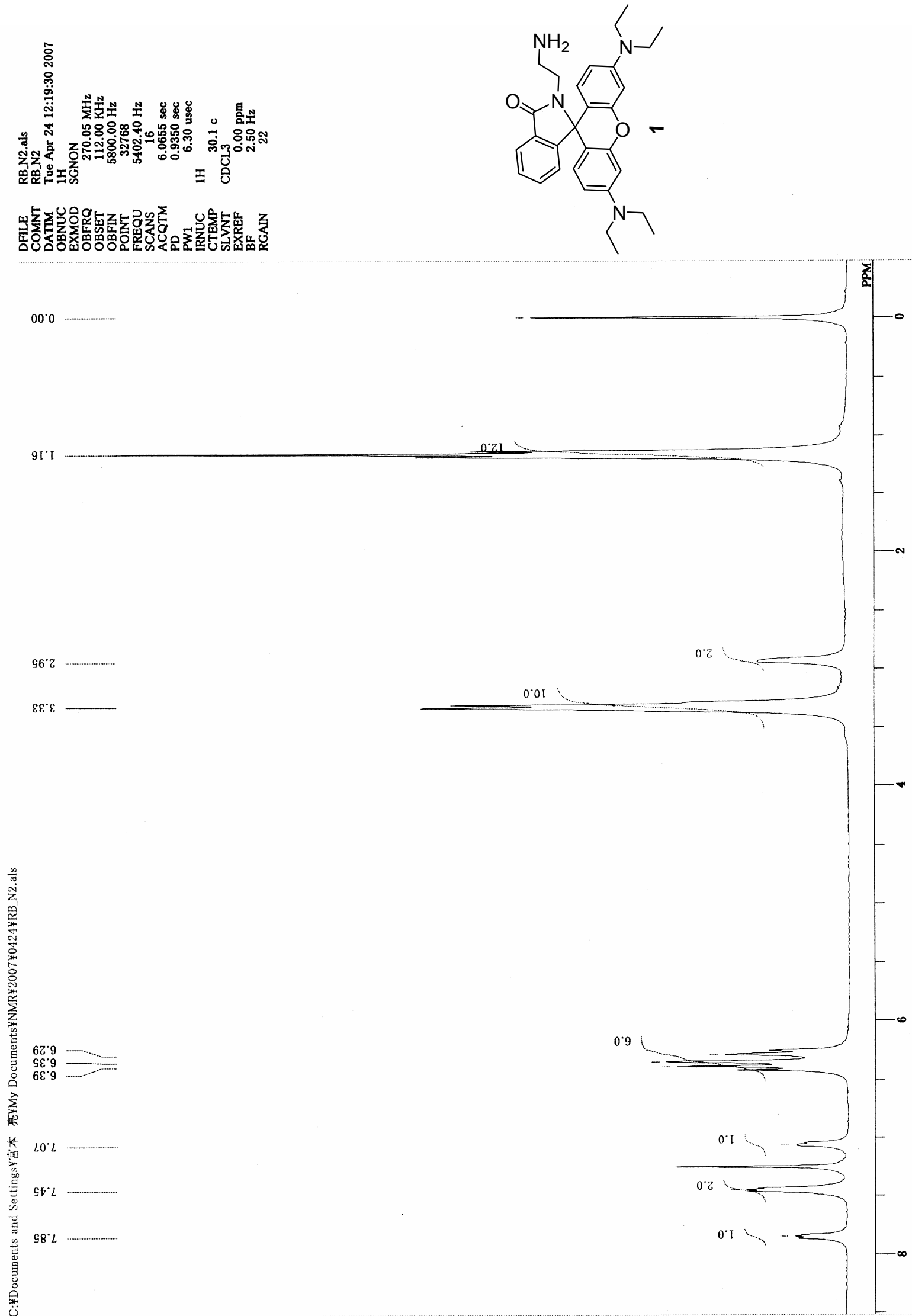

Figure S7. ${ }^{1} \mathrm{H}$ NMR spectrum of $\mathbf{1}$ in $\mathrm{CDCl}_{3}$. 

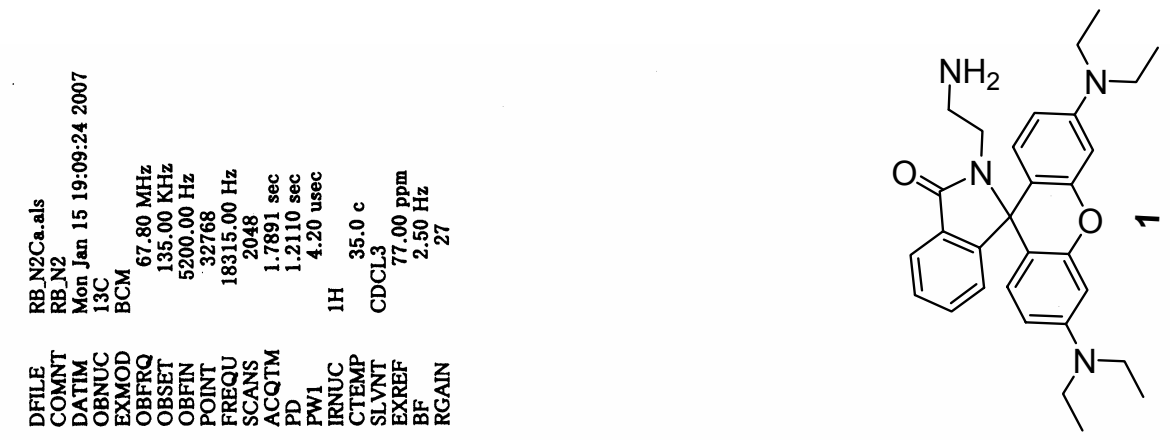

$\nabla L \cdot 2 I$

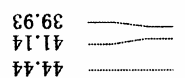
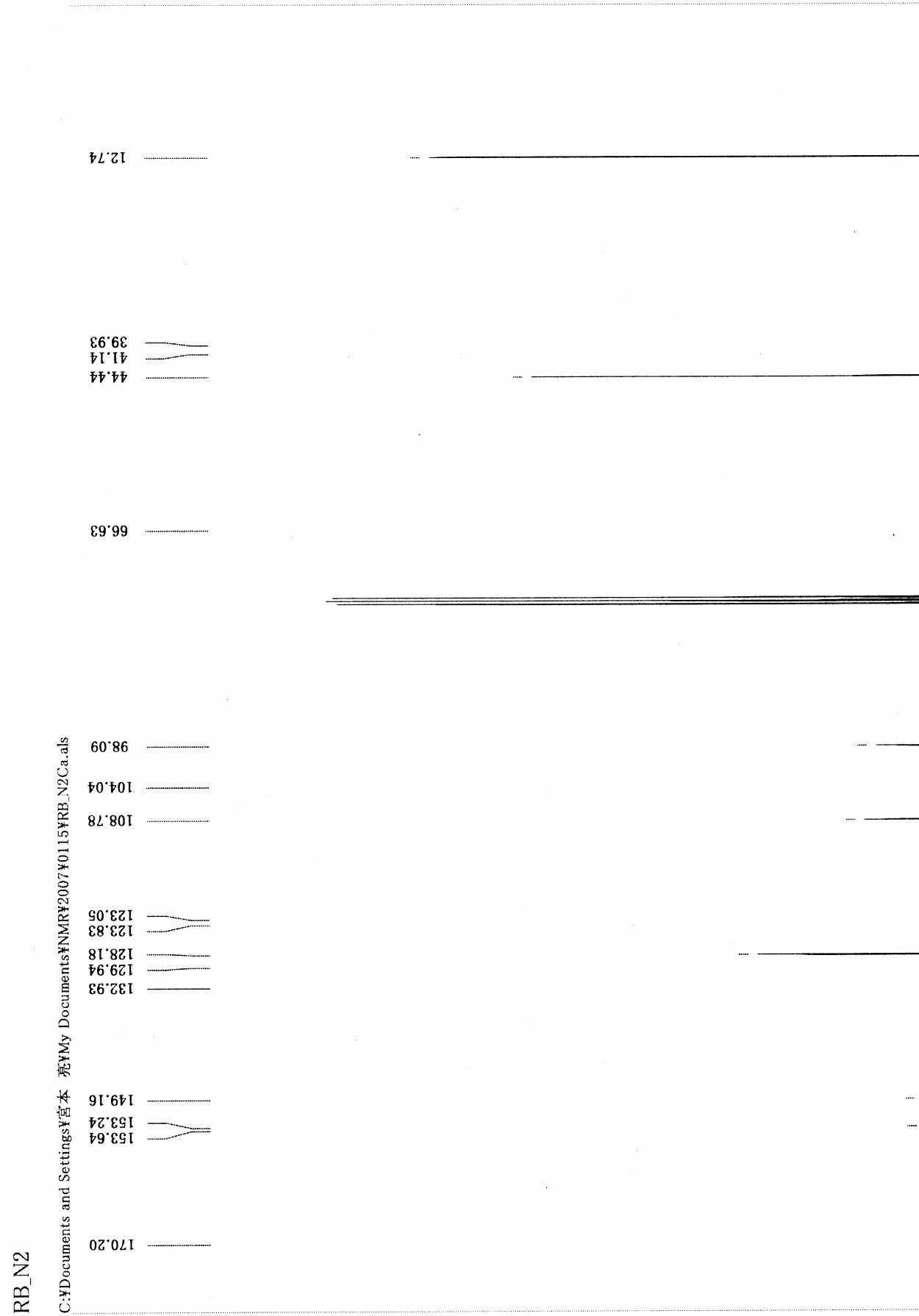

$+2$

